\title{
O MODELO DE PROCESSO COOPERATIVO E O DEVER DE FUNDAMENTAÇÃO DAS DECISÕES SOB A ÓTICA DA TEORIA DO DESENVOLVIMENTO MORAL DE LAWRENCE KOHLBERG
}

\author{
Vinicius Pinheiro Marques* \\ Sérgio Augusto Pereira Lorentino**
}

\section{RESUMO}

O CPC/2015 adotou o modelo do processo cooperativo imprimindo diversos deveres processuais às partes e aos magistrados impingiu o dever de proferir decisões adequadamente justificadas. O problema central da pesquisa, bem como seu objetivo, reside em analisar o nível de argumentação exigido pelo CPC/2015 à luz da teoria do desenvolvimento moral de Lawrence Kohlberg. Para alcançar tal desiderato, o método utilizado foi o dedutivo, com pesquisa de dados bibliográficos e com abordagem qualitativa. Ao final, concluiu-se que o modelo de processo cooperativo e o dever de fundamentação enquadram-se no nível de pósconvencionalidade da teoria de Lawrence Kohlberg.

Palavras-chave: Processo civil; cooperação; dever de fundamentação; argumentação moral; teoria da decisão judicial

\section{THE MODEL OF COOPERATIVE PROCESS AND THE DUTY OF FOUNDATION OF DECISIONS UNDER THE OPINION OF LAWRENCE KOHLBERG'S THEORY OF MORAL DEVELOPMENT}

\begin{abstract}
CPC/2015 adopted the model of the cooperative process, imposing various procedural duties on the parties and on the magistrates imposed a duty to make properly justified decisions. The central problem of the research is to analyze the level of argumentation required by the CPC/2015 in light of Kohlberg's theory of moral development. To achieve this, the method used was deductive, with a bibliographical data search and a qualitative approach. In the end, it was concluded that the cooperative process model and the duty to state the reasons are framed in the postconventional level of Kohlberg's theory.
\end{abstract}

Keywords: Civil lawsuit; cooperation; duty to state reasons; moral argumentation; theory of judicial decision

\section{INTRODUÇÃO}

\footnotetext{
* Doutor em Direito pela Pontifícia Universidade Católica de Minas Gerais (PUC MINAS). Professor do Programa de Pós-graduação em Prestação Jurisdicional e Direitos Humanos e do Curso de Direito da Universidade Federal do Tocantins (UFT). Presidente da Comissão de Ensino Jurídico da OAB Tocantins. Advogado. E-mail: viniciusmarques@uft.edu.br

** Doutor em Direito pela Pontifícia Universidade Católica de Minas Gerais (PUC MINAS). Professor do Curso de Direito da Universidade Federal do Tocantins (UFT). Advogado. E-mail: viniciusmarques@uft.edu.br
} 
Até a vigência do Código Buzaid (Código de Processo Civil de 1973), os modelos processuais civis se dividiam em dois: adversarial e inquisitorial. No primeiro, as partes autora e ré - mantinham-se num patamar de igualdade processual formal, e ao magistrado, sempre equidistante, caberia apenas julgar conforme as provas produzidas no processo mediante a paridade de armas. O modelo inquisitivo de processo, ciente das desigualdades processuais, conferiu aos magistrados mais poderes na busca da verdade e da promoção da justiça.

O Código de Processo Civil de 2015 inaugura um novo modelo processual denominado de cooperativo. Essa nova visão de processo parte do ideal de que todos devem cooperar para uma rápida solução da lide (art. $6^{\circ}$ do Código de Processo Civil). Assim o processo se evidencia como verdadeira comunidade de trabalho em que todas as partes têm deveres a cumprir, de modo que não existe centralidade dos atos a serem praticados.

Os deveres de lealdade e de boa-fé processual impuseram, ao que interessa no estudo em caso, uma série de deveres e observações com primazia a assegurar um contraditório amplo e efetivo. Dentre esses se destacam os deveres de comunicação, prevenção e alerta. A decisão judicial, enquanto coração do processo, não é mais vista como um ato isolado do magistrado, uma vez que as partes têm o direito de participar efetivamente na influência do convencimento, bem como da própria construção da decisão judicial. Nessa perspectiva o Código de Processo Civil de 2015 vislumbra a decisão não apenas nos seus elementos formais (relatório, fundamentação e dispositivo), esta deve ser adequadamente justificada como corolário da garantia constitucional fundamental inserida no art. 93, inciso IX, da Constituição Federal.

Diante dessas novas exigências de fundamentação, especialmente aquela prevista no art. $489, \S 1^{\circ}$, do Código de Processo Civil, surge o seguinte questionamento: Em qual nível de argumentação encontra-se o dever de fundamentação das decisões judiciais estampadas pela norma processual civil? Nesse sentido, o objetivo geral da pesquisa é analisar o nível de argumentação exigido pelo Código de Processo Civil de 2015 à luz da teoria do desenvolvimento moral de Lawrence Kohlberg.

O método da pesquisa será o dedutivo, porque se pretende levar as premissas pertinentes aos questionamentos, para, em momento posterior, formular conclusões válidas. $\mathrm{O}$ tipo de pesquisa quanto aos dados obtidos tem natureza documental indireta, uma vez que 
serão consultadas as leis e doutrinas contidas em livros e artigos científicos, todos disponibilizados em meio eletrônico ou físico (impresso). Diante dos dados levantados, será realizada uma abordagem qualitativa para interpretar e atribuir sentido aos fenômenos estudados; tem-se, ainda, a finalidade de explorar o assunto à luz da teoria da argumentação moral.

Para alcançar os objetivos traçados inicialmente, no primeiro item será estudada a formulação teórica de Lawrence Kohlberg com foco nos estágios e níveis de desenvolvimento moral, bem assim as características essenciais. No segundo item do artigo, serão explanadas as características essenciais do modelo de processo cooperativo, buscando correlacioná-lo ao dever de fundamentação das decisões judiciais. Por fim, e não menos importante, no último item será abordada a importância do dever de uma fundamentação judicial adequada, de modo a permitir a identificação da natureza desse dever com o nível de argumentação moral entabulada pela teoria de Kohlberg.

\section{TEORIA DO DESENVOLVIMENTO DA MORAL DE LAWRENCE KOHLBERG} (1927-1987)

As construções teóricas de Jean Piaget sobre as origens e desenvolvimento das estruturas mentais da moralidade influenciaram diversos pesquisadores. O psicólogo norteamericano Lawrence Kohlberg tornou-se notório em suas pesquisas acerca da moralidade porque se debruçou sobre as tendências morais entabuladas por Piaget, mas no campo da ciência avançou no sentido de ampliar e criar novas tipologias que se tornaram referências para estudos teóricos e práticos.

Souza e Vasconcelos (2009) apontam que Kohlberg iniciou suas pesquisas tendo como ponto de partida a tese de Piaget no sentido de que existe evolução natural do pensamento moral que se dá em estágios sequenciais e identificáveis. Entretanto, o pesquisador estadunidense percebeu que o último estágio $^{1}$ dificilmente seria encontrado nas idades apontadas por Piaget. Nesse diapasão, Kohlberg partiu da hipótese de que haveria um

\footnotetext{
${ }^{1}$ Sobre os estágios de desenvolvimento da consciência moral, a partir de Freitas (2002) é possível identificar que Piaget estabeleceu três estágios sequenciais: anomia, heteronomia e autonomia. No primeiro estágio do desenvolvimento moral do ser humano não haveria normas; no segundo, a norma é que direciona a consciência do sujeito, se ele deve fazer, ou não, determinada ação proveniente de outra(s) pessoa(s); por fim, a autonomia moral ocorre quando a consciência considera como necessário um ideal.
} 
caminho mais longo a ser percorrido. Para alcançar o desiderato de suas pesquisas, ele utilizou como método a realização de entrevistas com dilemas morais hipotéticos em que o sujeito participante deveria resolver um problema/conflito proposto, e deveria justificar a resposta ao caso apresentado ${ }^{2}$.

Não obstante, cumpre observar que os estudos de Kohlberg estavam ligados a uma vertente estruturalista no campo da psicologia da moralidade, e o ponto central da pesquisa residia no estudo do juízo moral de estrutura, ou seja, "se refere à argumentação ou à justificativa para a escolha realizada" (SOUZA; VASCONCELOS, 2009, p. 345).

Como resultado de suas pesquisas, Venturi (1995, p. 68) identifica que Kohlberg propõe um arranjo em seis estágios de raciocínio moral, agrupando-os de dois a dois em três níveis de moralidade: “os estágios 1 (orientação da punição e obediência) e 2 (relativista instrumental) correspondem ao nível pré-convencional; os estágios 3 (concordância interpessoal) e 4 (manutenção social) ao nível convencional; e os estágios 5 (contrato social) e 6 (princípio ético universal) ao nível pós-convencional”.

Nessa representação e escala sequencial, cada estágio corresponderia a um modo distinto de conceber e resolver os conflitos morais, bem como de operacionalizar a noção de justiça. A partir da análise de Freitag (1989), percebe-se que os estágios com numeração ímpar constituiriam as variantes heterônomas dos níveis de julgamento, em especial por predominar a percepção da regra ou convenção imposta, ao passo que os estágios com números pares constituiriam as variantes autônomas, uma vez que neles prevaleceria a dimensão de independência do indivíduo perante a norma ou regra estabelecida. Cada um desses estágios é analisado sob três óticas distintas: o conteúdo intrínseco do valor moral defendido, as justificativas apresentadas pelos sujeitos para defender esse conteúdo e a perspectiva sócio-moral da conscientização do sujeito.

Cabe ainda considerar que a moralidade vai se desdobrando e se construindo na passagem da heteronomia para a autonomia de cada nível, num processo desempenhado ativamente pelo sujeito, em que refaz a cada nível, um patamar de consciência mais abrangente e elevada.

\footnotetext{
${ }^{2}$ Um exemplo típico de situação de conflito a ser solucionado pelo entrevistado é o "Dilema de Heinz". Nesse caso, o personagem tem uma esposa que está muito doente e precisa de um remédio muito caro para salvar sua vida, e o farmacêutico não está disposto a negociar o preço. Nessa situação-problema, o que deve ser feito: furtar/roubar o remédio para salvar uma vida ou deixar a esposa morrer? O que deveria prevalecer, o direito à propriedade ou à vida humana?
} 
O desenvolvimento moral realizar-se-á na superação de um estágio ao outro e, consequentemente, na diferenciação das estruturas cognitivas. Isso significa dizer que o indivíduo encontra-se em evolução, quando na passagem de um estágio para o outro, consegue resolver melhor do que anteriormente a mesma espécie de problemas. "Ao fazer isso, a pessoa em crescimento compreende o seu próprio desenvolvimento moral como um processo de aprendizagem. Pois em cada estágio superior, o sujeito deve poder explicar até que ponto, estava insuficiente os juízos morais que considerava correto no estágio precedente" (HABERMAS, 1989, p. 155).

Quanto aos níveis da escala de Kohlberg, Freitag (1989) esclarece que no préconvencional o sujeito não tem a percepção do caráter convencional da norma, apenas a aceita como algo emanado de uma autoridade fora de sua consciência. No segundo nível, denominado convencional, a norma é reconhecida e respeitada pelo grupo. Por fim, no terceiro e último nível, reconhecido como pós-convencional, o sujeito consegue abstrair da norma reconhecida pelo grupo um ideal para, a partir dele, orientar suas ações por princípios éticos e autônomos. Na passagem dos estágios e níveis, observam-se elementos de transição que apontam para a sequencialidade e tendem a um progressivo equilíbrio entre o indivíduo e a sociedade. Nesse sentido, assiste razão à Biaggio (1999) ao afirmar que Kohlberg supõe a universalidade da sequência de estágios que culminam com a justiça. Desse modo, o sujeito é capaz de construir o conhecimento até atingir os níveis mais altos de julgamento moral.

A partir desses arranjos propostos, Lima (2004, p. 15) percebe que "a teoria kohlberiana é uma busca da definição científica e filosófica da moralidade, onde qualquer descrição da forma ou modelo de estrutura social é necessariamente dependente de estruturas cognitivas". Em outras palavras, os motivos de uma ação moral têm também um elemento cognitivo formal. Por fim, é possível reconhecer na teoria do desenvolvimento moral de Kohlberg que os estágios e níveis estão estruturados nas noções de justiça, os quais, por sua vez, são construídos em função das relações sociais.

\section{O MODELO DE PROCESSO COOPERATIVO INSTAURADO PELO CÓDIGO DE PROCESSO CIVIL}


Para organizar o processo existem variados modelos processuais que evoluíram em diferentes contextos históricos e sociais. Dentre os modelos de organização, os mais mencionados pelos estudiosos são: adversarial/liberal e inquisitorial/ socialização processual. Estes são definidos, basicamente, pela função que as partes desenvolvem no processo. No modelo adversarial, as partes estariam em posição de conflito direto, enquanto o órgão jurisdicional se manteria distante e inerte, apenas se responsabilizando em proferir a decisão; ao passo que no modelo inquisitorial o magistrado tem poderes para agir e intervir na relação processual, de modo a conduzir todas as ações para assegurar igualdade processual. É perceptível que os princípios inquisitivo e dispositivo não prevalecem por completo, apenas se sobressaem em diferentes momentos do processo.

\footnotetext{
A "dispositividade" e a "inquisitividade" podem manifestar-se em relação a vários temas: (a) instauração do processo; (b) produção de provas; (c) delimitação do objeto litigioso (questão discutida no processo); (d) análise de questões de fato e de direito; (e) recursos etc. Nada impede que o legislador, em relação a um tema, encampe o "princípio dispositivo" e, em relação ao outro, o "princípio inquisitivo". (DIDIER JR, 2011, on line, p. 02)
}

Obviamente, a ciência jurídica evoluiu com o decorrer dos séculos e, com isso, novos anseios sociais precisavam ser satisfeitos. O processo liberal que transcorria, quase exclusivamente com as partes produzindo provas para defender seus interesses e com o juiz responsável apenas por proferir a decisão, foi substituído, no final do século XIX, pela socialização processual. Esta tinha como base o princípio inquisitivo, ou seja, havia o protagonismo judicial no qual o Estado possuía plenos poderes sobre o processo.

\begin{abstract}
A partir da socialização processual, fase típica do século XX, que se inicia no final do século XIX e que ganha força a partir do delineamento do paradigma de Estado de Bem-Estar Social (Welfare State), com a decorrente ruptura da perspectiva liberal, ocorre um agigantamento da atuação estatal com: a) enorme preocupação com questões sociais; b) fortalecimento do executivo no quadro da tripartição de funções; c) defesa de um perfil clientelista do cidadão (cidadão hipossuficiente); d) ingerência demasiada do Estado nas relações jurídicas. (THEODORO JÚNIOR et al, 2015, p. 54)
\end{abstract}

Apesar de os defensores do protagonismo processual alegarem que este servia como ferramenta para a transformação social, o modelo inquisitivo começou a ser fortemente criticado, pois o poder concentrado nas mãos do magistrado gerava consequências arriscadas devido à sua arbitrariedade. Fazia-se necessária, então, a incorporação a um novo modelo que 
fosse superior aos anteriores. Uma organização em que houvesse o policentrismo processual, ou seja, que nenhum dos sujeitos tivesse mais poder do que o outro. A partir dessa concepção, nasceria então uma verdadeira comunidade de trabalho.

\begin{abstract}
A denominada "comunidade de trabalho" (Arbeitsgemeinschaft) entre juiz e partes (e seus advogados), idealizada pela doutrina tedesca e que, levada a sério, permitiu na Alemanha uma formação unitária dos futuros magistrados e advogados, impediu que a relação entre estes se transformasse em conflito de categorias, além de delinear na doutrina processual a idealização do policentrismo processual, que afasta qualquer concepção de protagonismo. (THEODORO JÚNIOR et al, 2015, p. 56)
\end{abstract}

A partir desse momento, em que houve a necessidade do rompimento com os já ultrapassados princípios inquisitivo e dispositivo, surge aquele que é o objeto imediato deste capítulo: o princípio da cooperação. Ao observar a etimologia da palavra "Cooperação", torna-se perceptível o objetivo desse princípio processual que tem origem no direito alemão. O prefixo "co" significa "conjunto" e associado com a derivação do latim "operatione" representa "ação em conjunto". Há aqui uma alteração na forma como os sujeitos processuais se relacionam e de suas funções na fase processual.

No modelo cooperativo, as partes e os magistrado estão em igual posição, o que torna o processo mais harmônico e justo, pois eles adquirem deveres um para com o outro, mantendo verdadeiro diálogo.

Muitos doutrinadores sustentam que o modelo processual está intimamente relacionado com o contexto social e político do país em que atua. Desse modo, um Estado autoritarista geralmente utilizará como organização o princípio inquisitivo; um Estado Democrático incorporar-se-á à cooperação.

Muito congruente foi a escolha do legislador em ter atribuído ao Código de Processo Civil de 2015 o modelo cooperativo, haja vista ser este o primeiro Código de Processo Civil desenvolvido após o longo período em que o Brasil sofreu com regime ditatorial. Portanto, a nova lei está em conformidade com o atual Estado Democrático de Direito estabelecido pela Constituição Federal, de 1988. Antes de a nova Constituição entrar em vigor, o magistrado desempenhava um papel diferente do que se pode ver atualmente, ele tinha a lei como única fonte para solucionar os conflitos; desse modo, agia de forma mais legalista.

O Código de Processo Civil de 2015 carrega uma feitura mais condizente aos pressupostos democráticos, considerando que os dois anteriores Códigos de Processo Civil 
brasileiro foram redigidos em contextos políticos autoritários, respectivamente, no Estado Novo, em 1939; e no Regime Militar, em 1973. As normas fundamentais do Código de Processo Civil de 2015 traduzem o caráter democrático que enseja a dinâmica dos ritos processuais, prestigiando os princípios da publicidade, da cooperação, da participação, da razoabilidade, e, sobretudo, de uma possível solução consensual dos conflitos.

No Brasil, vem de longe a descrença no legislador e o receio cultuado em relação ao aplicador da lei. Rui Barbosa, em Oração aos Moços, em 1920, já propalava esse ceticismo, quase que em tom profético, que a história infelizmente confirmaria. "É verdade - dizia ele que a execução corrige ou atenua, muitas vezes, a legislação de má nota. Mas, no Brasil, a lei se deslegitima, anula e torna inexistente não só pela bastardia da origem, senão ainda pelos horrores da aplicação".

É de grande alento que o novo Código de Processo Civil, no contexto atual da democracia brasileira, traga como marca a sensibilidade da efetiva realização de direitos harmonizados com as garantias constitucionais. Na nossa época, em que as instituições firmam os pressupostos da democracia, não cabem mais argumentos de autoridade ou justificações suportadas em motivações subjetivas, muitas vezes desalojadas da realidade e carentes de fundamentação. É necessário e essencial a utilização, sem exceção, de argumentos portadores de força racional. E os argumentos serão sempre construídos e reconstruídos em um processo de interação comunicativa, na qual a força do melhor argumento, via de regra, em que pese o bom senso, deve prevalecer sobre qualquer outra forma de coerção, seja ela originária da força, da autoridade ou da exclusiva subjetividade de quem decide.

O Código de Processo Civil de 2015 ao exigir das partes e do próprio juízo uma atitude de participantes (Art. $5^{\circ}$ ), está a evocar a necessidade de que todos os envolvidos no processo orientem-se em vista do entendimento, o que significa, em termos, que cooperem entre si $\left(\right.$ Art. $\left.6^{\circ}\right)$. A orientação de ação em vista à participação e à cooperação somente é possível mediante o pressuposto de que a linguagem constitui-se como condição de possibilidade do entendimento. A solução da lide é o telos do processo, da mesma forma que o entendimento é telos da linguagem. Desses dois pressupostos é possível esperar que o entendimento gere, ao final, consenso ou acordo entre as partes. Aliás, este é um dos pontos inovadores no Código de Processo Civil de 2015 ao enfatizar, amiúde, a possibilidade de as 
partes colocarem fim ao conflito por meio da mediação linguística (BANNWART JÚNIOR, 2017, p. 9-12).

A cooperação proporciona que as partes tenham participação ampla na construção das decisões, pois possibilita um diálogo processual entre os litigantes e o magistrado. Desta feita, é proporcionada ao juiz uma análise mais correta sobre os fatos, para que este produza decisões bem fundamentadas que não gerem surpresas para as partes. Ademais, há a valorização da boa-fé processual que inibe atitudes protelatórias das partes, atitudes estas que podem ser impedidas coercitivamente pelo juiz.

A primeira disposição, em que se pode observar explícita influência da cooperação no Novo Código de Processo Civil, é o artigo 60: "Todos os sujeitos do processo devem cooperar entre si para que se obtenha, em tempo razoável, decisão de mérito justa e efetiva”. Portanto, os litigantes e o juiz estão no mesmo patamar, vivenciando uma relação policêntrica.

Dentre os princípios basilares, que regem o modelo cooperativo, é primordial citar o devido processo legal, disposto no artigo $5^{\circ}$, inciso LIV, da Constituição Federal, de 1988: "ninguém será privado da liberdade ou de seus bens sem o devido processo legal". Este tem como propósito reduzir o Poder Estatal, para que a trajetória até a solução do conflito de interesses seja mais justa e isonômica. Outras garantias constitucionais, como, por exemplo, a ampla defesa e o contraditório, também desempenham importante papel no processo cooperativo.

As influências dos princípios constitucionais e dos direitos fundamentais no direito processual civil são de extrema importância, porque o processo se transforma numa ferramenta de imensurável valor para a conversão do direito abstrato em concreto. Dessa interação começa a se modificar a forma como é visto o devido processo legal, o qual deve ser dinâmico sob todos os aspectos jurídicos e analisado pela interpretação constitucional, que valoriza os direitos fundamentais. Essa constitucionalização é denominada justo processo.

Na verdade, “a noção básica do 'justo processo' e a consequente identificação de suas "garantias mínimas" resultam da "tradição angloamericana do due process of law ". A ideia do giusto processo se justifica para deixar clara a possibilidade de atribuir ao processo os valores que carregam o adjetivo justo (ou équo, équitable, fair, faires), ao mesmo tempo em que se pretende afastar da noção de devido processo legal remetida "ao contexto cultural do Estado de Direito (Rechtsstaat, État Légal), em que o processo era concebido unicamente como um anteparo ao arbítrio estatal". Para tanto, é necessário assegurar ao processo uma deontologia pautada no respeito aos direitos essenciais da pessoa, tendo em vista que o direito fundamental 
ao processo justo visa a tutelar um mínimo inderrogável e inviolável de garantias constitucionais, cuja ética é edificada no "conjunto dos valores fundamentais da civilização e da democracia”. (FRANCO, 2015, on line, p. 04)

O justo processo tem como objetivo a equidade, haja vista a valorização dos princípios democráticos. O magistrado e as partes formam uma comunidade de trabalho, na qual a contribuição daquelas é imprescindível para formular a decisão, pois, na comparticipação, o juiz não profere decisões de forma isolada, mas sim por meio de um diálogo paritário. Portanto, pode-se visualizar que o Estado Constitucional está intimamente relacionado ao modelo cooperativo de processo.

Nesse contexto, em que o processo é organizado pelo modelo cooperativo, além do devido processo legal, outro princípio constitucional que possui destaque é o do contraditório. Ele está disposto no art. 5, inciso LV, Constituição Federal, de 1988, e aduz "aos litigantes, em processo judicial ou administrativo, e aos acusados em geral que são assegurados o contraditório e a ampla defesa, com os meios e recursos a ela inerentes". O contraditório é considerado como um desdobramento de outros dois princípios, supramencionados, de extrema importância para a ciência processual: $\mathrm{O}$ devido processo legal e a ampla defesa.

$\mathrm{O}$ contraditório tem o objetivo de assegurar às partes o direito de defender seus interesses no processo, para que elas tenham abrangente oportunidade de se manifestar em relação às decisões que possam prejudicá-las. Fernando Gonzaga Jayme, em seu artigo intitulado "O princípio do contraditório no projeto do Novo Código de Processo Civil", apresenta uma excelente conceituação sobre o contraditório em consonância com o Estado Democrático de Direito:

\footnotetext{
O conceito de contraditório adequado ao Estado Democrático de Direito pressupõe a análise das bases lançadas pela teoria do processo como procedimento realizado em simétrico contraditório entre as partes. Iguais oportunidades de participação entre os interessados é elemento essencial do processo e imprescindível para assegurar o acesso à ordem jurídica justa e a legitimidade do processo de produção dos atos decisórios. (JAYME, 2014, on line, p. 02)
}

Para o referido autor, o contraditório pode ser classificado em duas dimensões diferentes. A primeira é a estática, nesta é atribuído aos litigantes o direito de ouvir e de serem ouvidos, de ter conhecimento e participação no processo e da simples citação e intimação. Esta dimensão diz respeito a uma manifestação ultrapassada do princípio. A dimensão 
dinâmica se utiliza de algumas características da estática; entretanto, naquela os litigantes possuem mais prerrogativas, principalmente no que diz respeito à influência que podem exercer durante a construção da decisão, por meio de manifestações na fase de instrução probatória.

Na dimensão dinâmica também é atribuída às partes a oportunidade de fiscalizar o exercício do órgão jurisdicional, pois, assim, o juiz não poderá proferir decisões-surpresa. Todos os aspectos que influenciem na decisão devem ser discutidos amplamente entre o magistrado e as partes. Portanto, o magistrado tem a obrigação de analisar todas as provas e argumentos demonstrados pelos litigantes respondendo às alegações fundamentadamente. Assim, pode-se observar que no Estado Democrático de Direito o contraditório é tridimensional e apresenta os seguintes elementos:

\begin{abstract}
a) direito das partes à ciência, informação e participação no processo em simétrica paridade (dimensão estática ou formal); b) prerrogativa de influência e de controle das partes na construção do conteúdo da decisão judicial (dimensão dinâmica ou material); c) direito de as partes terem analisados e considerados os seus argumentos e provas, em correlação com o dever do órgão jurisdicional de efetivamente apreciar todas as questões deduzidas pelas partes, resolvendo o caso concreto unicamente com base nos resultados decorrentes da atividade dos interessados ao provimento (dimensão comparticipativa, na qual a motivação decisória é elemento do contraditório). (JAYME, 2014, on line, p. 9-10)
\end{abstract}

Destarte, o princípio do contraditório impõe ao magistrado que ele abra espaço para que todos os aspectos influenciadores da resolução da demanda sejam amplamente discutidos no decorrer do processo pelas partes.

O Código de Processo Civil de 2015 baseou-se neste modelo de processo, no qual o princípio do contraditório exerce importante papel para a construção das decisões. Após a entrada em vigor do novo diploma processual, os magistrados precisaram se habituar a uma forma de atuação completamente diferente da que era regulada pelo Código de Processo Civil de 1973.

Antigamente, era garantida aos litigantes tão somente a simples bilateralidade do processo; além disso, o magistrado ficava em posição superior às partes, enquanto estas mantinham um conflito isolado. Entretanto, a nova modalidade de contraditório atribui ao processo características mais democráticas, pois proporciona que a lei processual se adapte ao texto constitucional. 
Um aspecto muito importante do Código de Processo Civil de 2015 é a vedação das decisões-surpresa, característica inovadora do diploma legal, pois o Código de Processo Civil de 1973 não tem nenhuma disposição correspondente ao art. 10 do Novo Código de Processo Civil de 2015. O artigo 10 aduz que "O juiz não pode decidir, em grau algum de jurisdição, com base em fundamento a respeito do qual não se tenha dado às partes oportunidade de se manifestar, ainda que se trate de matéria sobre a qual deva decidir de ofício”. Como já mencionado, o magistrado se vê obrigado, então, a manter uma comunicação harmônica com as partes, o que dá ao processo o condão de democratizar o Poder Judiciário.

\section{DEVER DE FUNDAMENTAÇÃO DA DECISÃO JUDICIAL}

O magistrado representa importante papel no triângulo de sujeitos processuais e, para que seus objetivos de solucionar as lides sejam realizados, ele se manifesta por seus pronunciamentos definidos em lei. Em especial quanto à sentença, seus elementos estão dispostos no art. 489, incisos I, II e III, do Código de Processo Civil e são: relatório, fundamentos e dispositivo. O mesmo artigo que enumera os elementos fundamentais da sentença também traz importante disposição, em seu $\S 1^{\circ}$, sobre a obrigatoriedade de decisões bem fundamentadas.

Art. 489. São elementos essenciais da sentença: [...]

$\S 10$ Não se considera fundamentada qualquer decisão judicial, seja ela interlocutória, sentença ou acórdão, que:

I - se limitar à indicação, à reprodução ou à paráfrase de ato normativo, sem explicar sua relação com a causa ou a questão decidida;

II - empregar conceitos jurídicos indeterminados, sem explicar o motivo concreto de sua incidência no caso;

III - invocar motivos que se prestariam a justificar qualquer outra decisão;

IV - não enfrentar todos os argumentos deduzidos no processo capazes de, em tese, infirmar a conclusão adotada pelo julgador;

V - se limitar a invocar precedente ou enunciado de súmula, sem identificar seus fundamentos determinantes nem demonstrar que o caso sob julgamento se ajusta àqueles fundamentos;

VI - deixar de seguir enunciado de súmula, jurisprudência ou precedente invocado pela parte, sem demonstrar a existência de distinção no caso em julgamento ou a superação do entendimento.

$\S 2$ o No caso de colisão entre normas, o juiz deve justificar o objeto e os critérios gerais da ponderação efetuada, enunciando as razões que autorizam a interferência na norma afastada e as premissas fáticas que fundamentam a conclusão. § $30 \mathrm{~A}$ decisão judicial deve ser interpretada a partir da conjugação de todos os seus elementos e em conformidade com o princípio da boa-fé. 
É perceptível, então, que as decisões, sejam elas sentenças, interlocutórias ou acórdão precisam, obrigatoriamente, de fundamentos. A fundamentação exigida pelo Código Processual de 2015 vai muito além de uma simples reprodução do texto legal.

\begin{abstract}
A exigência de fundamentação das decisões judiciais (CRP, art. 205/1) ou da "motivação de sentenças" radica em três razões fundamentais: (1) controlo da administração da justiça; (2) exclusão do carácter voluntarístico e subjectivo do exercício da actividade jurisdicional e abertura do conhecimento da racionalidade e coerência argumentativa dos juízes; (3) melhor estruturação dos eventuais recursos, permitindo às partes em juízo um recorte mais preciso e rigoroso dos vícios das decisões judiciais recorridas. (CANOTILHO, 1999, p. 621).
\end{abstract}

De fato, a obra clássica de Taruffo (2005) divisou as funções endoprocessual e extraprocessual da motivação. A primeira, enquanto requisito técnico, assegura que a motivação é útil (a) à parte que pretenda impugná-la, porque o conhecimento da motivação da decisão facilita a individuação do erro; e (b) ao juízo de impugnação (recursal, mais apropriadamente quanto ao direito brasileiro) porque viabiliza o reexame da decisão impugnada. A segunda dá ensejo (a) ao controle externo das razões de motivação; (b) à indução ao julgador de demonstrar a validade racional de suas razões diante do sistema jurídico; e (c) à demonstração da eficácia persuasiva do precedente invocado como razão de decidir. Daí sua importância também para a decisão que não mais desafia recurso, como expressão da máxima garantia de justificação, o que há décadas já era no Brasil ressaltado.

\begin{abstract}
Ao ângulo em que nos colocamos, ressalta-se a insuficiência dessa maneira de equacionar o problema e a sua inidoneidade para atender aos postulados do Estado de Direito. Não é a circunstância de estar emitindo a última palavra acerca de determinado litígio que exime o órgão judicial de justificar-se. Muito ao contrário, é nesse instante que a necessidade da justificação se faz particularmente aguda: o pronunciamento final, exatamente por se destinar a prevalecer em definitivo, e nesse sentido representa (ou deve representar) a expressão máxima da garantia, precisa, mais do que qualquer outro, mostrar-se apto a corresponder à função delicadíssima que lhe toca. Não é admissível que a garantia se esvazie, se despoje de eficácia, no momento culminante do processo mediante o qual é chamado a atuar. (MOREIRA, 1978, p. 118).
\end{abstract}

Além disso, o art. 11 do Novo Diploma Processual Civil também legisla sobre o mesmo aspecto: “Todos os julgamentos dos órgãos do Poder Judiciário serão públicos, e fundamentadas todas as decisões, sob pena de nulidade". 
O legislador ao determinar no Código de Processo Civil de 2015 que todas as decisões devem ser fundamentadas, teve a intenção de enfatizar disposição já prevista na Constituição Federal da República, de 1988. Esta, no seu art. 93, inciso IX, já previa que as decisões dos órgãos do Poder Judiciário deveriam ser fundamentadas, sob pena de nulidade:

\begin{abstract}
Art. 93. Lei complementar, de iniciativa do Supremo Tribunal Federal, disporá sobre o Estatuto da Magistratura, observados os seguintes princípios: [...] IX - todos os julgamentos dos órgãos do Poder Judiciário serão públicos, e fundamentadas todas as decisões, sob pena de nulidade, podendo a lei limitar a presença, em determinados atos, às próprias partes e a seus advogados, ou somente a estes, em casos nos quais a preservação do direito à intimidade do interessado no sigilo não prejudique o interesse público à informação;
\end{abstract}

Para que o magistrado profira uma decisão fundamentada, de acordo com as disposições legais, é necessário que, antes, realize uma interpretação e correlação entre o caso concreto e a legislação cabível. Para isso, ele deverá observar minunciosamente as provas pertencentes ao caso e interpretar os aspectos fáticos. Posteriormente, deverá analisar as normas legais que se encaixam ao caso em tela. Ao realizar essas análises, o magistrado estará efetuando a racionalidade das decisões judiciais.

Conforme preconiza Kochem (2015), a justificação racional é exigida pelo duplo aspecto determinativo da decisão judicial, que diz respeito à delimitação dos fatos e ao apontamento das normas jurídicas aplicáveis. Portanto, a racionalidade das decisões judiciais depende da relação feita entre a interpretação de normas do direito e dos fatos alegados no processo.

Em síntese, a doutrina identifica os seguintes componentes para uma fundamentação
racional das decisões judiciais: “(a) a enunciação das escolhas desenvolvidas pelo
órgão judicial para (a1) individualização das normas aplicáveis; (a2) acertamento
das alegações de fato; (a3) qualificação jurídica do suporte fático; (a4)
consequências jurídicas decorrentes da qualificação jurídica do fato; (b) o contexto
dos nexos de implicação e coerência entre tais enunciados e (c) a justificação dos
enunciados com base em critérios que evidenciam ter a escolha do juiz ter sido
racionalmente correta". (KOCHEM, 2015, on line, p. 05)

Desta feita, as normas não têm sentido algum por si sós. Não basta apenas que sejam indicadas para resolver determinado caso concreto, há a necessidade de que o juiz interprete os dispositivos legais, pois, sem isso, as normas são apenas textos. Além disso, "se os preceitos jurídicos (termos-textos) em sua ampla maioria das vezes possuem mais de uma 
interpretação legítima, só há(veria) uma forma de eliminar o arbítrio judicial: através da fundamentação exaustivamente adequada e coerente". (SCALABRIN; SANTANNA, 2016, on line, p. 3)

Nesse diapasão, a hermenêutica jurídica representa importante papel para a compreensão do juiz diante do caso concreto, pois a fundamentação é a exteriorização desse complexo fenômeno hermenêutico, de modo que caberá ao magistrado demonstrar o surgimento da norma naquela situação.

Ademais, há forte influência do contraditório, devido ao fato de que o juiz deve demonstrar suas motivações justificando, especificamente, por que aceitou os argumentos e provas da parte vencedora e, o mais importante, os motivos que o levaram a não acolher as exposições da parte vencida. Portanto, com a intenção de preservar esse importante direito, a falta de fundamentação gera nulidade.

A importância de decisões fundamentadas se dá por vários fatores. A fundamentação inibe a arbitrariedade dos magistrados, uma vez que necessitam fazer uso da hermenêutica e demonstrar suas motivações de forma esclarecedora. Isso preserva o direito de as partes terem amplo conhecimento sobre o motivo pelo qual suas pretensões não foram atendidas e, consequentemente, há certa diminuição nos recursos interpostos, pois os sujeitos processuais conseguem compreender melhor as decisões proferidas. Entretanto, um dos mais importantes aspectos é a valorização de um julgamento isonômico que está em consonância com o Estado Democrático de Direito.

\section{CONCLUSÃO}

O Código de Processo Civil de 2015 em sua essência adotou o modelo de processo cooperativo, pressupondo ser este uma comunidade de trabalho em que todos devem cooperar para rápida solução do litígio. Nesse sentido, o modelo de processo cooperativo pressupõe um policentrismo, no qual todas as partes têm suas funções, e uma não é mais nem menos importante que a outra. Esse modelo processual exige uma dinâmica e intensa relação dialógica entre as partes, bem como o dever de agir com lealdade e boa-fé, para que construam em conjunto a decisão judicial. Às partes, autor e réu, deve ser oportunizado contraditório dinâmico e efetivo a fim de propiciar momento e fala e possibilidade de 
convencimento do magistrado. A este cumpre observar deveres de comunicação, informação e prevenção, ex vi, a vedação de decisão-surpresa.

Nessa linha de que existem deveres processuais, o Código de Processo Civil de 2015 ultrapassou a ideia de que a decisão formal deve apenas conter relatório, fundamentação e dispositivo. O novo diploma processual, tonalizado pelos matizes do processo cooperativo, impõe que a decisão judicial esteja devidamente fundamentada (art. 489, $\S 1^{\circ}$, do Código de Processo Civil de 2015).

A fundamentação das decisões, mais do que uma exigência própria do Estado Democrático de Direito, é um direito fundamental do cidadão. Fundamentar significa não apenas transcrever a regra legal/constitucional ao caso em lide. Todas as decisões devem estar justificadas, de modo que se possa demonstrar a invocação de razões e oferecimento de argumentos de caráter jurídico. $\mathrm{O}$ fator relevante das decisões judiciais encontra-se justamente na necessidade de motivação/justificação do que foi pronunciado ao caso, sob apreciação do Poder Judiciário. Trata-se, portanto, de verdadeira cláusula geral que vem proteger as pessoas contra julgamentos arbitrários.

Analisando a norma do Código de Processo Civil de 2015 que estabelece sobre os deveres de fundamentação adequada, sob o prisma da Teoria do desenvolvimento moral de Lawrence Kohlberg, parece que o diploma processual civil brasileiro exige um nível de argumentação pós-convencional. Não se admite que os juízos de decisão formulados pelos magistrados estejam limitados a interesses individuais ou egocêntricos (nível préconvencional) ou que apenas se limite à reprodução da lei por uma aceitação social (convencional). Os fundamentos de uma decisão adequada devem estar contidos em princípios universais abstraídos das fontes do Direito, mas com prevalência e reconhecimento dos direitos humanos e garantias constitucionais fundamentais, sempre argumentados e dialogados num contexto social (no caso em lide, traduzidos dentro do processo como comunidade de trabalho), de modo que o agir/decidir possa valer como um princípio ético universal com a finalidade de construir a justiça.

No estágio pós-convencional, a justificativa para uma tomada de decisão ou propósito de ação será sempre referendada pelo desempenho discursivo, com o objetivo de formar consensualmente a vontade e a opinião, sob a tutela de uma única coerção: a coerção do melhor argumento. Esse nível, ápice da consciência moral, é o patamar que Habermas coloca, 
do ponto de vista filosófico, a sua ética do discurso - modelo de normatividade próprio das sociedades modernas que atingiram o nível pós-convencional. Se os problemas e os conflitos que tocam a contemporaneidade são demandas de uma sociedade pós-convencional, resta que o Judiciário seja igualmente capaz de apresentar soluções em nível de uma normatividade pós-convencional. O novo paradigma subscrito no atual Código de Processo Civil parece representar, do ponto de vista empírico, a confirmação de que o Direito, em sua estrutura teórica, se movimenta na direção da pós-convencionalidade.

\section{REFERÊNCIAS}

BANNWART JÚNIOR, Clodomiro José. O novo Código de Processo Civil sob a égide da democracia. In: FUGA, Bruno; ANTUNES, Thiago C. Recursos em Espécie no Código de Processo Civil. Estudos avançados sobre o sistema recursal civil brasileiro. Londrina: Editora Thoth, 2017.

BIAGGIO, Angela Maria Brasil. Universalismo versus relativismo no julgamento moral. Psicologia: Reflexão e Crítica, Porto Alegre, v.12, n.1, p. 5-20, dez. 1999.

BRASIL. Constituição Federal de 1988. Disponível em:

<http://www.planalto.gov.br/ccivil_03/constituicao/ConstituicaoCompilado.htm>. Acesso em: 15/8/2018.

BRASIL. Lei no 13.105, de 16 de março de 2015. Código de Processo Civil. Disponível em: <http://www.planalto.gov.br/ccivIl_03/_Ato2015-2018/2015/Lei/L13105.htm>. Acesso em: $15 / 8 / 2018$.

CANOTILHO, Joaquim José Gomes. Direito constitucional e teoria da constituição. 3. ed. Coimbra: Almedina, 1999.

DIDIER JR, Fredie. Os três modelos de direito processual: inquisitivo, dispositivo e cooperativo. Doutrinas Essenciais de Processo Civil, São Paulo, v. 1, p. 1347-1359, out. 2011. Disponível em: <www.rtonline.com.br>. Acesso em: 15/8/2018.

FRANCO, Marcelo Veiga. Dimensão dinâmica do contraditório, fundamentação decisória e conotação ética do processo justo: breve reflexão sobre o art. 489, § 1. ${ }^{\circ}, \mathrm{IV}$, do novo CPC.

Revista de Processo, São Paulo, v. 247, p. 105-36, set. 2015. Disponível em: <www.rtonline.com.br>. Acesso em: 15/8/2018.

FREITAG, Barbara. A questão da moralidade: da razão prática de Kant à ética discursiva de Habermas. Tempo Social, São Paulo, v. 1, n. 2, p. 7-44, jul./dez. 1989. 
FREITAS, Lia Beatriz de Lucca. Autonomia moral na obra de Jean Piaget: a complexidade do conceito e sua importância para a educação. Educar em Revista, Curitiba, n. 19, p. 11-22. 2002.

HABERMAS, Jürgen. Consciência Moral e Agir Comunicativo. Tradução: Guido Antônio de Almeida. Rio de Janeiro: Tempo Brasileiro, 1989.

JAYME, Fernando Gonzaga. O princípio do contraditório no projeto do Novo Código de Processo Civil. Revista de Processo, São Paulo, v. 227, p. 335-359, jan. 2014. Disponível em: 〈www.rtonline.com.br>. Acesso em: 15/8/2018.

KOCHEM, Ronaldo. Racionalidade e decisão - a fundamentação das decisões judiciais e a interpretação jurídica. Revista de Processo, São Paulo, v. 244, p. 59-83, jun. 2015.

Disponível em: <www.rtonline.com.br>. Acesso em: 15/8/2018.

LIMA, Vanessa Aparecida Alves de. De Piaget a Gilligan: retrospectiva do desenvolvimento moral em psicologia um caminho para o estudo das virtudes. Psicologia, Ciência e Profissão, Brasília, v. 24, n. 3, p. 12-23, set. 2004.

MOREIRA, José Carlos Barbosa. A motivação das decisões judiciais como garantia inerente ao Estado de Direito. Revista Brasileira de Direito Processual, Rio de Janeiro, v. 16. p. 111125. 4. trim. 1978.

SCALABRIN, Felipe; SANTANNA, Gustavo. A legitimação pela fundamentação: anotação ao art. $489, \S 1 .^{\circ}$ e $\S 2 .^{\circ}$, do novo código de processo civil. Revista de Processo, São Paulo, v. 255, p. 17-40, maio 2016. Disponível em: <www.rtonline.com.br>. Acesso em: 15/8/2018.

SOUZA, Leonardo Lemos de; VASCONCELOS, Mario Sergio. Juízo e ação moral: desafios teóricos em psicologia. Psicologia \& Sociedade, Florianópolis, v. 21, n. 3, pp. 343-352, dez. 2009.

TARUFFO, Michele. La motivazione della sentenza. In: MARINONI, Luiz Guilherme (coord.). Estudos de direito processual civil. São Paulo: Ed. RT, 2005.

THEODORO JÚNIOR, Humberto; NUNES, Dierle; BAHIA, Alexandre Melo Franco; PEDRON, Flávio Quinaud. Novo CPC - Fundamentos e sistematização. Rio de Janeiro: Forense, 2015.

VENTURI, Gustavo. O universalismo ético: Kohlberg e Habermas. Lua Nova: Revista de Cultura e Política, São Paulo, n. 36, p.67-84, 1995. 